\title{
A conceptual flowsheet for heap leaching of platinum group metals (PGMs) from a low- grade ore concentrate
}

\author{
James M. Mwase ${ }^{1}$, Jochen Petersen ${ }^{1}$, J.J. Eksteen ${ }^{2}$ \\ 1. Department of Chemical Engineering, University of Cape Town, South Lane Road, Upper Campus, \\ Rondebosch, Cape Town, 7700, Republic of South Africa \\ 2. Process Division, Western Platinum Limited, Private Bag X508, Marikana, 0284, Republic of South Africa; \\ Jacques.Eksteen@lonmin.com
}

The original version of this article is available in Hydrometallurgy 111-112 (2012) 129-135

\begin{abstract}
This research proposes a new conceptual process to economically extract platinum group metals (PGMs), and as a secondary aim, base metals (BMs) from a low-grade concentrate originating from typical PGM concentrator plants. Slurry made from the concentrate was coated onto granite pebbles and packed into a column, in which it was bioleached with a mixed culture of thermophiles and mesophiles at $65^{\circ} \mathrm{C}$. After 30 days the extractions achieved were $52 \%$ copper, $95 \%$ nickel and $85 \%$ cobalt. The residual concentrate material was subsequently subjected to a cyanide leach also in a packed column operating at a room temperature of $23^{\circ} \mathrm{C}$. After 21 days $20.3 \% \mathrm{Pt}, 87 \%$ $\mathrm{Pd}$ and $46 \% \mathrm{Rh}$ were extracted. Using these results and projected extractions over longer operating times, a conceptual flowsheet was proposed for a possible process route to recover PGM values circumventing the problematic smelter route for this material.
\end{abstract}

Keywords: PGMs, heap leaching, low-grade ore concentrate, cyanide, thermophiles, bioleaching

\section{Introduction}

During the milling and flotation of platinum group metal (PGM) concentrates, particularly of Upper Group 2 (UG2) ores, cleaning flotation can often deliver both a high-grade and a low-grade concentrate which may be dispatched as a blend to the smelter. When UG2 ores are milled, or when the PGMs occur as slow-floating minerals, or when the PGMs are difficult to liberate, the secondary cleaner flotation cells often produce a low-grade concentrate, that can be associated

\footnotetext{
${ }^{1}$ Tel +00 2721650 3804, Fax + 002721650 5501, JM.Mwase@uct.ac.za

${ }^{2}$ Dr. JJ Eksteen is a Visiting Professor to the University of Stellenbosch, South Africa
} 
with high chromite grades (in the case of UG2) or high pyrrhotite dilution (in the case of Platreef). This invariably leads to high smelting costs (low-grade) and smelter integrity risks (due to the chromite) or large environmental impact (due to large quantities of FeS per PGM-unit which has to be converted to Fe-bearing slag and $\mathrm{SO}_{2}$ gas). This is the case at Western Platinum Limited (WPL) where the concentrator plant produces, as a by-product, a low-grade concentrate from the secondary cleaning circuit containing up to $29 \mathrm{~g} / \mathrm{t}$ of platinum group metal (PGMs), $0.36 \%$ copper and $0.74 \%$ nickel and less than $0.5 \% \mathrm{~S}$. In the case of UG2 ores, this low-grade concentrate is also associated with chromite mineral content, and therefore poses smelting difficulties and a high processing cost per unit of PGM. However, due to the high tonnage production of this material, the amounts of valuable metals accumulated on an annual basis can be quite considerable. Unlike the copper and gold industry, where heap and dump leaching have found wide spread use in extracting value from low-grade ores and concentrates, no such methods have been widely applied at an industrial level in the PGM industry.

Successful industrial scale $\mathrm{Ni}-\mathrm{Cu}$ bacterial heap leaching of ore has only recently been implemented at Talvivaara in Finland (Riekkola-Vanhanen, 2010), whilst Jinchuan Nickel company has also piloted Ni-Cu heap bioleaching of low-grade ore using mesophiles (Qin et al., 2009). In this regard this study proposes a low-cost hydrometallurgical process consisting of a heap bioleach process to first extract the base metals (BMs), followed by a caustic rinse of residue material and a heap cyanidation process to subsequently extract the PGMs. The present study represents only part of the work done in a broader exploratory investigation to evaluate and compare various options for treating the low-grade ore concentrate (Mwase, 2009). This proposed flowsheet has been conceptualised for integration into a standard platinum process which involves milling, flotation, smelting, acid pressure leaching of the matte and finally high pressure chloride leaching of high-grade PGM residue material. Running parallel to this, any low-grade concentrate produced can be processed via the method proposed herein.

\section{Theory}

\subsection{Cyanidation}

The cyanidation process has proved to be an effective and economical option for successful gold extraction over the decades. For gold, it works well at ambient conditions and, depending on the 
grade of ore, cyanide leaching can be carried out in open vats or open dumps and heaps (Chamberlain and Pojar, 1984; Adams, 2005; Mular et al., 2002). In conjunction with this, adsorption onto carbon is an economic and efficient recovery method. In addition free cyanide and cyanide complexed with base metals or any unwanted elements can be reclaimed a number of available technologies (Lien, 2008; Cohn et al., 2001; Gupta and Mukherjee, 1990). Similarly, in the adsorption to carbon process, the stripped carbon can be used up to two to three times without regenerating or can be regenerated for re-use (Chamberlain and Pojar, 1984).

Furthermore, from a variety of reagents investigated as alternatives (sodium bisulphide, thiosulphate, thiourea, hypochlorite and bromine/bromide solutions) cyanide has proven to be the most effective (Mwase, 2009) and the most environmentally acceptable reagent (Mular et al., 2002). This is due to the fact that it undergoes natural oxidation converting the cyanide to $\mathrm{CO}_{2}$ and $\mathrm{N}_{2}$. Based on this process, there are currently a number of commercially available processes, both chemical and biological, to treat cyanide solution effluents and decontaminate concentrates from cyanide leaching operations (Gupta and Mukherjee, 1990; Yeddou et al., 2010; Akcil, 2002; Akcil, 2003; Barriga-Ordonez et al., 2006; Kitis et al., 2005; Parga et al., 2003; Fatma et al., 2009; Dash et al., 2009; Patil and Paknikar, 2000; Ozel et al., 2010). Aside from this, waste effluents can be treated using physical methods such as carbon sorption and the use of membrane technology (Deveci, 2006; Lien, 2008; Gonen et al., 2004).

Experimentally it has been shown that PGM cyanidation occurs in the same manner as that of gold. Platinum(II) and palladium(II) form stable complexes with cyanide, namely $\left[\mathrm{Pt}(\mathrm{CN})_{4}\right]^{2-}$ and $\left[\mathrm{Pd}(\mathrm{CN})_{4}\right]^{2-}(\mathrm{McInnes}$ et al., 1994). As in the case of gold the reactions for PGMs can take place at ambient conditions (Torres and Costa, 1997; McInnes et al., 1994) and the reactions reported follow kinetics described by the Elsner equation (Chen and Huag, 2006):

$$
\begin{aligned}
& 2 \mathrm{Pt}_{(\mathrm{s})}+8 \mathrm{NaCN}_{(\mathrm{aq})}+\mathrm{O}_{2(\mathrm{~g})}+2 \mathrm{H}_{2} \mathrm{O}_{(\mathrm{l})} \rightarrow 2 \mathrm{Na}_{2}\left[\mathrm{Pt}(\mathrm{CN})_{4}\right]_{(\mathrm{aq})}+4 \mathrm{NaOH}_{(\mathrm{aq})} \\
& 2 \mathrm{Pd}_{(\mathrm{s})}+8 \mathrm{NaCN}_{(\mathrm{aq})}+\mathrm{O}_{2(\mathrm{~g})}+2 \mathrm{H}_{2} \mathrm{O}_{(\mathrm{l})} \rightarrow 2 \mathrm{Na}_{2}\left[\mathrm{Pd}(\mathrm{CN})_{4}\right]_{(\mathrm{aq})}+4 \mathrm{NaOH}_{(\mathrm{aq})} \\
& 4 \mathrm{Rh}_{(\mathrm{s})}+24 \mathrm{NaCN}_{(\mathrm{aq})}+3 \mathrm{O}_{2(\mathrm{~g})}+6 \mathrm{H}_{2} \mathrm{O}_{(\mathrm{l})} \rightarrow 4 \mathrm{Na}_{3}\left[\mathrm{Rh}(\mathrm{CN})_{6}\right]_{(\mathrm{aq})}+12 \mathrm{NaOH}_{(\mathrm{aq})}
\end{aligned}
$$

Previous studies on PGM cyanidation (Torres and Costa, 1997; McInnes et al., 1994; Chen and Huag, 2006) were successful when they were carried out at high temperatures and pressures under 
oxidizing conditions. While Chen and Huang (2006) contend that under ambient conditions the reaction between cyanide and PGMs does not even take place, others have reported a reaction but poor extraction levels ((Torres and Costa, 1997; McInnes et al., 1994). It was concluded that these conditions were necessary to facilitate the cyanidation of PGMs when they were in metallic/alloy form, typical of high grade residues from acid pressure leaching of flotation concentrates. The PGMs in the flotation concentrate used in this study occur in sulphide/telluride/selenide/arsenide/ferroalloy forms (Schouwstra and Kinloch, 2000) and are hence already in an oxidised state. Thus it has been postulated that a cyanidation process will successfully achieve the desired target extractions, even under ambient temperature and atmospheric pressure. Additionally Chang and Huang (2006), and Torres and Costa (1997) both use high cyanide concentrations (>6 g/L) as compared to those used in gold leaching, around 0.25 g/L (Chamberlain and Pojar, 1984). No explanation was offered for this but perhaps such high concentrations are needed to successfully drive the reaction between cyanide and the PGMs. In gold leaching such high cyanide concentrations are used when leaching less cyanide soluble gold tellurides and arsenides, and when there is above $0.5 \%$ copper in the ore (Marsden and House, 2006; Gupta and Mukherjee, 1990; Adams, 2005).

Cyanide is not selective to PGMs and will readily complex with the BMs, resulting in significant consumption of the cyanide lixiviant if BMs are leached together with PGMs. Additionally BMs readily adsorb to carbon thus posing potential interference to the recovery of PGMs. Copper concentrations of around 100 ppm have been known to have a detrimental effect on the carbon adsorption of gold from cyanide leachate (Marsden and House, 2006) and this may also be the case in recovering PGMs from the cyanide solution using the adsorption to carbon method. The presence of iron in the concentrate may result in co-complexation with the PGM cyanide ions, an occurrence observed in copper leaching with cyanide (Gupta and Mukherjee, 1990). This would result in PGM losses or the need for additional stages (processes) to recover the PGMs. Furthermore, if a significant portion of the PGMs are occluded in the BM sulphide matrices, as reported (Schouwstra and Kinloch, 2000) for this type of ore, a BM extraction process preceding the cyanide leach becomes a necessity. However the extent of BM extraction required depends on the mineralogical profile; if high cyanide soluble BM minerals are present, the extraction must be high, if they are slow leaching in cyanide then a lower degree is required. But this will be also gauged against how much of the PGMs they occlude. 


\subsection{Bioleaching and Biooxidation}

Bioleaching in heaps and dumps, and biooxidation in heaps and tanks are comparatively environmentally friendly and well established technologies in the economical recovery of copper and uranium from low-grade ores, as well as in the pre-treatment of refractory gold ores respectively (Dresher, 2004; Gonzalez et al., 2004; Rawlings and Johnson, 2007). It is proposed that a variation of these processes be investigated as the method for extracting the BMs from the low-grade ore concentrate prior to PGM leaching with cyanide.

In microbially assisted leaching, iron oxidizing bacteria catalyse the oxidation of reduced sulphur compounds such as sulphides to elemental sulphur or sulphates by the ferrous/ferric couple. Additionally, sulphur oxidising bacteria are employed to catalyse oxidation of elemental sulphur to produce sulphuric acid. This provides the acidic environment for the process to take place, and aids mineral dissolution as well. The process can be summarised by the equations below (Gonzalez et al., 2004; Bosecker, 1997):

$$
\begin{aligned}
& \mathrm{FeSO}_{4}+\mathrm{O}_{2}+2 \mathrm{H}_{2} \mathrm{SO}_{4} \rightarrow 2 \mathrm{Fe}_{2}\left(\mathrm{SO}_{4}\right)_{3}+2 \mathrm{H}_{2} \mathrm{SO}_{4} \\
& \mathrm{MeS}+2 \mathrm{Fe}_{2}\left(\mathrm{SO}_{4}\right)_{3} \rightarrow \mathrm{MeSO}_{4}+2 \mathrm{FeSO}_{4}+\mathrm{S}^{0} \\
& 2 \mathrm{~S}^{0}+3 \mathrm{O}_{2}+\mathrm{H}_{2} \mathrm{O} \rightarrow 2 \mathrm{H}_{2} \mathrm{SO}_{4}
\end{aligned}
$$

The microorganisms of particular interest to this study are a group categorised as thermophiles, because of their ability to operate optimally in the temperature range of $60-85^{\circ} \mathrm{C}$. As with most leach reactions, operating at an elevated temperature increases the rate of the reaction i.e. increases the rate at which the copper and nickel are leached. Furthermore, a large portion of the copper in the concentrate material is suspected to be in the form of chalcopyrite, whereas the nickel is largely in the form of pentlandite (Evans, 2007; Schouwstra and Kinloch, 2000). Chalcopyrite and pentlandite are leached according to equation (5) as follows (Watling, 2008; Kinnunen et al., 2006):

$$
\mathrm{CuFeS}_{2}+4 \mathrm{Fe}^{3+} \rightarrow \mathrm{Cu}^{2+}+5 \mathrm{Fe}^{2+}+2 \mathrm{~S}^{0}
$$




$$
2(\mathrm{NiFe})_{9} \mathrm{~S}_{8}+18 \mathrm{Fe}_{2}\left(\mathrm{SO}_{4}\right)_{3} \rightarrow 45 \mathrm{FeSO}_{4}+16 \mathrm{~S}^{0}+9 \mathrm{NiSO}_{4}
$$

Normally chalcopyrite does not leach effectively at temperatures below $40^{\circ} \mathrm{C}$ due to the formation of a "passivating" layer on the surface of the unreacted material; coating it and preventing or slowing further leaching (Gericke et al., 2010; Dew et al., 2000). The layer restricts attachment of bacteria, transport of nutrients, oxidants and reaction products to and from the mineral surface (Stott et al, 2000). This layer comes either in the form of jarosite $\left(\mathrm{KFe}_{3}\left(\mathrm{SO}_{4}\right)_{2}(\mathrm{OH})_{6}\right)$, iron-hydroxy precipitates (such as goethite, $\mathrm{FeO}(\mathrm{OH})$ ) or elemental sulphur formed in the reaction (Leahy and Schwarz 2009). Additionally, jarosite formation can cause loss of ferric ions from solution and clogging of pore spaces, preventing solution flow on both a micro and macro-scale (Leahy and Schwarz, 2009). However, elevated temperatures have been observed to destabilize the passivating layer, allowing chalcopyrite leaching to proceed at appreciable rates (Bosecker, 1997; Petersen and Dixon, 2002; Kelly et al., 2008).

Further to this, if sulphide oxidation is incomplete the resultant products are polythionates and elemental sulphur (Riekkola-Vanhanen, 2010) which can passivate the target minerals. On top of this the elemental sulphur would react with the cyanide in the second phase leach to form thiocyanate thus consuming cyanide that would otherwise be needed for PGM leaching. However as most iron oxidising bacteria used commercially are also sulphur oxidising (Rawlings and Johnson, 2007) this problem may not arise. If it does arise, it can be mitigated by adapting a dedicated culture to elemental sulphur and inoculating it into the heap along with the regular culture.

The bioleach experiment in this study uses the proprietary GEOCOAT ${ }^{\odot}$ process (Harvey et al., 2008; Rawlings and Johnson, 2007) developed by GeoBiotics LLC as a basis. The key aspects of these processes are the coating of fine concentrate material onto sterile support media (usually barren or waste rock, or waste sulphide ore) and then stacking in a heap. The mass ratio of concentrate to media is typically in the range of $1: 5$ to $1: 10$ and the support media is carefully and uniformly sized $(-25+6 \mathrm{~mm})$. This results in sufficient inter-spatial channels in the heap to provide low resistance to air and solution flow and sufficient contact between the solution and the target minerals. Mixed cultures of mesophilic and thermophilic microorganisms are used in the oxidation and leaching of sulfide minerals in an engineered heap environment, at temperatures of up to $75^{\circ} \mathrm{C}$, with materials of construction and excessive evaporation losses becoming the limiting factor for 
heap leach applications. The process thus combines faster reactions at high temperatures with the low cost of heap leaching to present a route for the commercial leaching of copper from low-grade concentrates containing chalcopyrite. Furthermore, the leaching of sulphide minerals with oxygen as the terminal electron acceptor is an exothermic reaction which produces adequate heat that can be used to maintain the optimal temperature for leaching (Dixon, 2000). Additionally, this heat can be conserved in the heap by controlling the rate at which the leach solution is irrigated from the top of the heap in conjunction with the rate of air up flow in the heap (Petersen and Dixon, 2002; Rawlings and Johnson, 2007).

However, in the experimental portion of this study the temperature was kept constant using a heating jacket, as unheated columns have a high surface area to mass ratio and low thermal inertia compared to industrially sized heaps.

\subsection{Reactor Configuration}

The reactor choice of a heap proves to be a superior option compared to a conventional stirred tank reactor for processing the ore concentrate. Considering a stirred tank reactor requires a solid to liquid ratio of about 10-30\% and keeping in mind that the residence time to commercially extract the PGMs at ambient temperature may be long (Cabri, 1989), and given the high throughput and low grade of the material and the energy costs of mechanical agitation, it is unlikely to be a feasible option for this type of ore concentrate. Heap reactors, on the other hand, although characterised by long leach times, are capable of handling large tonnages of concentrate at a time hence increasing the chances of profitability as witnessed in several successful copper and gold heap leaching operations (Gupta and Mukherjee, 1990; Mular et al., 2002). Furthermore, heaps facilitate the contact of small amounts of liquid with large amounts of solid material and require no mechanical agitation, thus resulting in low capital and operating costs (Dixon and Petersen, 2002).

\section{Materials and Methods}

\subsection{Ore Concentrate Split and Profile}

The concentrate material assays (Tables 1 and 2) were as follows: 
Table 1: Platinum Group Metals

\begin{tabular}{llll}
\hline $\mathbf{g} / \mathbf{t}$ & $\mathbf{P d}$ & $\mathbf{R u}$ & $\mathbf{R h}$ \\
\hline $\mathbf{P t}$ & 8.2 & 4.4 & 2.6 \\
\hline 12 & \\
\hline
\end{tabular}

Table 2: Base and Gangue Elements

\begin{tabular}{lllllllll}
\hline$\%$ & & & & & & & \\
$\mathbf{C u}$ & $\mathbf{N i}$ & $\mathbf{F e}$ & $\mathbf{C o}$ & $\mathbf{M g}$ & $\mathbf{A l}$ & $\mathbf{S i}$ & $\mathbf{C a}$ & $\mathbf{C r}$ \\
\hline 0.36 & 0.74 & 6.7 & 0.011 & 15 & 1.1 & 25 & 1.5 & 0.44 \\
\hline
\end{tabular}

Western Platinum Limited is engaged in mining ore from the Merensky and UG2 Reefs of the Bushveld Igneous Complex in South Africa (Cabri, 2002). However, this particular material originated from the Merensky Reef. The PGMs in this ore occur largely as sulphide minerals and partially as tellurides, arsenides, and ferroalloys (Seymour and O'Farrelly, 2001; Schouwstra and Kinloch, 2000). They mainly deport to the base metal sulphide minerals or are interlocked at the BM-silicate grain boundary and are hence recoverable via flotation, after sufficient liberation. Similarly, the base metals of value and interest occur largely as sulphide minerals as well. Copper and nickel in particular occur as chalcopyrite and pentlandite respectively (Schouwstra and Kinloch, 2000).

\subsection{Concentrate Receipt and Preparation}

The concentrate material was received mildly damp in a $200 \mathrm{~L}$ drum. To ensure homogeneity before attempting to sample from the container, the sample was thoroughly blended and split into test work charges using laboratory riffle and rotary splitters. A size analysis using a Malvern Master Sizer Long Bench S and standard vibrating wet screening test revealed the material size distribution was $97 \%$ passing $75 \mu \mathrm{m}$ and $88 \%$ passing $45 \mu \mathrm{m}$.

\subsection{Heap Bioleach}

At bench scale, heap reactors are investigated conventionally using packed columns (Figure 1). A sample of approximately $600 \mathrm{~g}$ of ore concentrate was made into slurry using deionised water in a ratio of 5:3 (solid to liquid) by mass and coated onto approximately $3.5 \mathrm{~kg}$ of granite pebbles before being carefully packed into the column. The feed solution containing $2 \mathrm{~g} / \mathrm{L} \mathrm{Fe}\left(1 \mathrm{~g} \mathrm{Fe}^{3+}\right.$ and $1 \mathrm{~g} \mathrm{Fe}^{2+}$ ) and $10 \mathrm{~g} / \mathrm{L}$ sulphuric acid was fed at a rate of $1 \mathrm{~L} /$ day (translated from standard industrial flow rate of $51 / \mathrm{m}^{2} / \mathrm{h}$ ) and the column was aerated at a rate of $130 \mathrm{~mL} / \mathrm{min}$. The column was 
operated at a temperature of $65^{\circ} \mathrm{C}$ and inoculated with mixed culture of thermophiles and mesophiles in which Sulfolobus metallicus and Ferroplasma cupricumulans were the most prevalent species, accounting for almost $100 \%$ of the microbial population. The species in the culture were identified and quantified by using quantitative real time polymerase chain reaction (qRT PCR) using species specific primer sets.

Inoculation into the column was done only when the temperature reached $65^{\circ} \mathrm{C}$. Samples of 15 $\mathrm{mL}$ were withdrawn from the effluent every 24 hours for the first 4 days and every 4 days after that for 30 days for atomic absorption spectroscopy (AAS) analysis of $\mathrm{Cu}, \mathrm{Ni}, \mathrm{Co}$ and $\mathrm{Fe}$. The $\mathrm{pH}$ and redox potential (vs $\mathrm{Ag} / \mathrm{AgCl}$ ) were measured using a standard $\mathrm{pH}$ meter and redox probe. Additional $5 \mathrm{~mL}$ samples were withdrawn for microscopic inspection, to ensure the culture community of microorganisms was thriving. After the experiment the material was recovered from the support media by washing in water and sieving simultaneously and recovery of the concentrate from the wash water by filtration. The residue was washed with deionised water and alkaline water to remove residual acid in preparation for the cyanide leach and oven dried. Sub-samples were obtained to perform solid assays for PGMs, BMs and gangue elements.

The PGMs in the residual concentrate were assayed by Fire-Assay using nickel sulphide as a collector, followed by crushing, leaching and dissolution of the nickel sulphide in aqua regia and analysis for PGMs using inductively coupled plasma optical emission spectrometry (ICP-OES). For the BMs the samples underwent alkaline peroxide fusion followed by acid dissolution in aqua regia and ICP-OES analysis. 


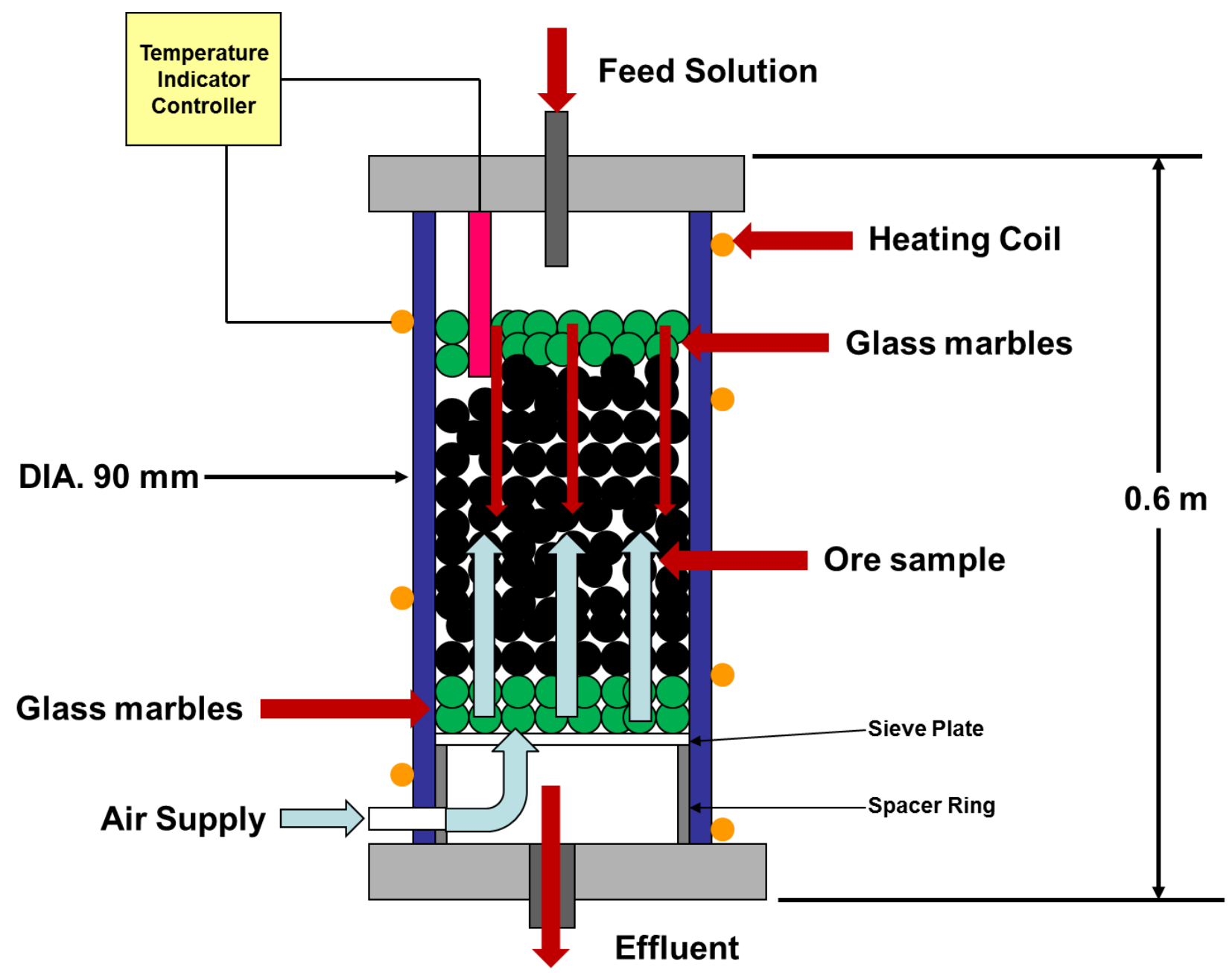

Figure 1: Schematic drawing of equipment used for leaching tests

\subsection{Cyanidation}

The residual material from the above experiment was coated onto support rock in the same manner as described above, using the same reactor configuration, and leached with a $0.15 \mathrm{M}$ solution of sodium cyanide at a room temperature $\left(23^{\circ} \mathrm{C}\right)$ and pressure. The sodium cyanide solution was prepared using buffered water, prepared by dissolving $10.6 \mathrm{~g}$ of $\mathrm{Na}_{2} \mathrm{CO}_{3}$ and $8.4 \mathrm{~g}$ of $\mathrm{NaHCO}_{3}$ salts per $1 \mathrm{~L}$ of deionsed water. This ensured the $\mathrm{pH}$ of the solution was above 10 and maintained at that level for the duration of the experiment. The solution was fed to the column at a rate of 1 L/day, but unlike the bioleach experiment was recycled for 7 days before replacing with fresh solution. The experiment continued for 21 days. Samples were withdrawn at regular intervals for inductively coupled plasma mass spectrometry (ICP-MS) analysis of PGMs, BMs and gangue metals, and the $\mathrm{pH}$ was measured using a standard $\mathrm{pH}$ meter. 


\section{Results and Discussion}

\subsection{Heap Bioleach}

This system has shown great potential for processing the ore concentrate at a commercial level; AAS analysis showed that extractions of $52 \% \mathrm{Cu}, 95 \% \mathrm{Ni}$ and $85 \%$ Co were achieved in 30 days (Figure 2). The success of this process can be attributed to the fact that the BMs occurred largely or entirely as sulphide minerals (Schouwstra and Kinloch, 2000), which respond well to bioleaching. Addressing the matter of the lower copper extractions; it is noted that that the experiment ran for 30 days at a temperature of $65^{\circ} \mathrm{C}$. Thermophilic microorganisms are known to operate optimally in the range of $70-85^{\circ} \mathrm{C}$ (Petersen and Dixon, 2002; Dew et al., 2000). Other similar studies (Petersen and Dixon, 2002; Harvey et al., 2002; Dew et al. 2000) have achieved higher copper extractions over longer leaching times and at higher temperatures from ores and concentrates where copper occurred as chalcopyrite. This strongly suggests that with longer leaching time and higher operating temperatures, the copper extractions from this concentrate can equal those of the nickel and cobalt. Further to this, the copper extraction graph (Figure 2) shows that it is still on a linear slope and likely to continue increasing to commercially viable levels. However it should be noted that in this context the leaching of copper is secondary to the platinum extraction, and if the remaining copper is relatively inert to cyanide leaching and does not heavily consume the lixiviant, then complete extraction may not be necessarily required. 


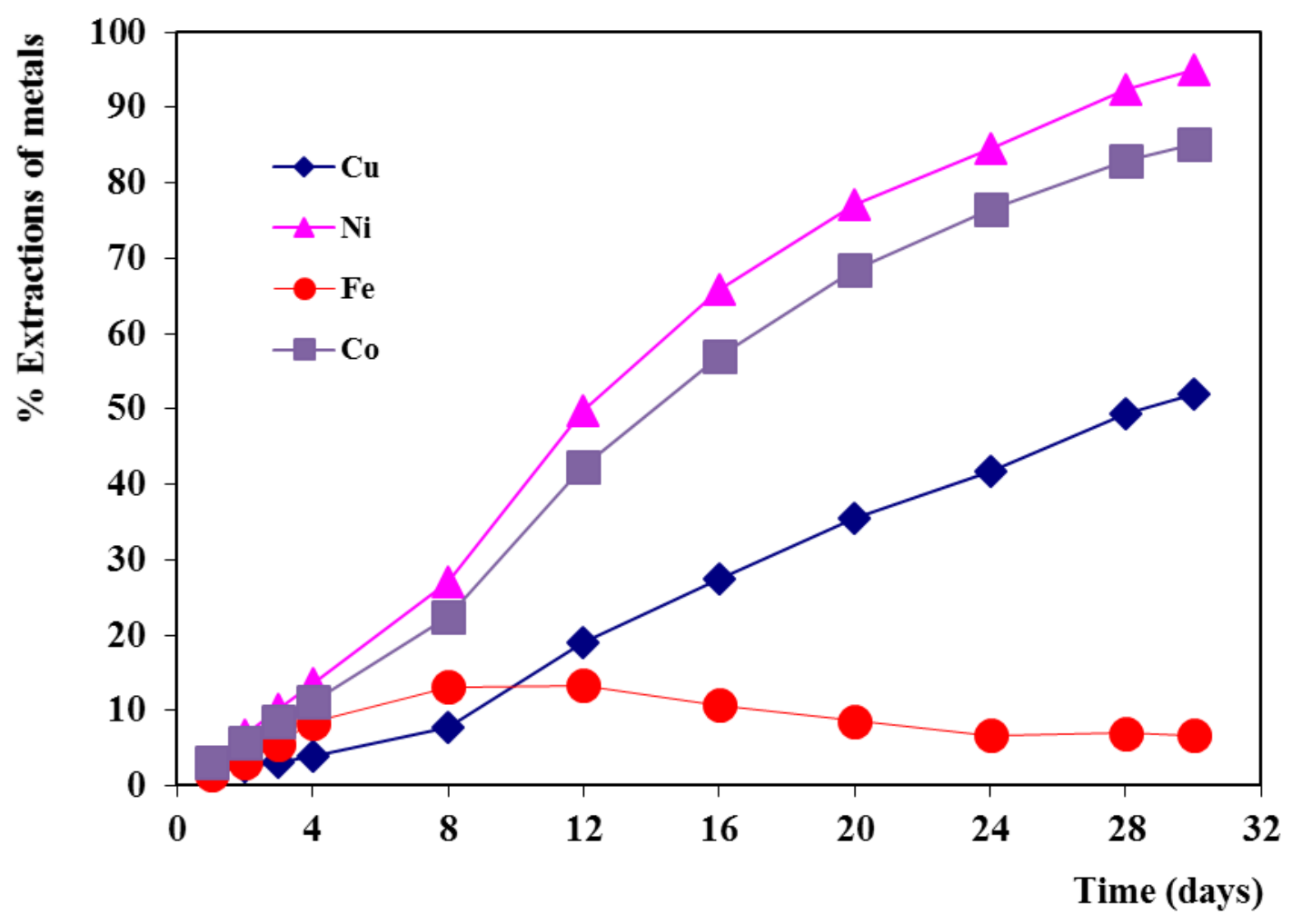

Figure 2: Percentage extractions from bioleach process

The low amount of iron present in solution suggests that under the prevalent conditions, of temperature, the iron precipitated out from the feed solution which had $2 \mathrm{~g} / \mathrm{L}$ of Fe to start with. The Fe curve in Figure 2 represents the iron in solution above the initial $2 \mathrm{~g} / \mathrm{L}$ in the feed solution. Additionally, along with this process, iron may have been leached from the concentrate and immediately precipitated out. This chemical process may have been microbially assisted (Ding et al., 2007). Figure 3 shows an initial dip in Eh during the first 4 days, thereafter there is a rapid increase suggesting the microbial culture had fully adapted to the concentrate at this point and was effectively oxidising the $\mathrm{Fe}^{2+}$ to $\mathrm{Fe}^{3+}$. 


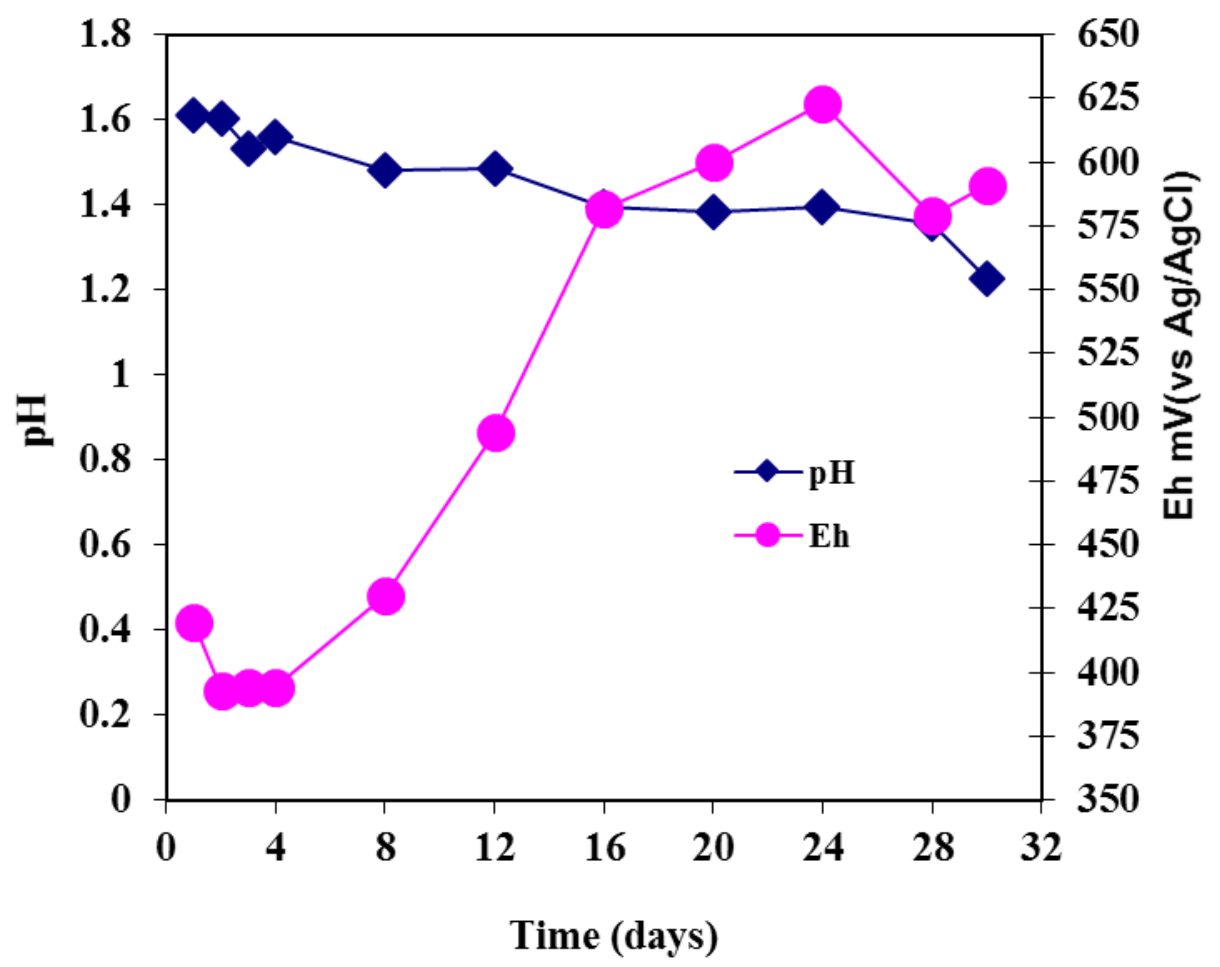

Figure 3: pH-redox potential profile

Solid assays conducted on the residual material of the heap bioleach process preceding the cyanide heap leach, revealed there was co-extraction of PGMs (Table 3). However the extraction of the more valuable platinum does not appear to be very significant. An analysis on the leach liquors to determine if any PGMs had been solubilised was not conducted, hence it cannot be determined conclusively if this extraction was due to solubilisation or loss of the concentrate material during the processes of recovering it from the support media and filtration. The percentage extractions of $\mathrm{Rh}$ and $\mathrm{Ru}$ in this experiment are similar to those experienced in sulphate based base metal refineries, as reported by Dorfling et al. (2011). Given the quantities of Rh and Ru extracted, and the possibility of these quantities increasing over longer leaching times, there is good reason to investigate the recovery of the $\mathrm{Rh}$ and Ru before or after BM recovery. Current technology and research is focusing on the use of ion exchange, precipitation and solvent extraction to recover $\mathrm{Rh}$ and Ru from chloride and nitrate media (Kononova et al., 2011; Els et al., 2000; Bernardis et al., 2005; Seymour and O'Farrelly, 2001). The use of these methods as a means of recovery from a sulphate media is also a possibility. 
Table 3: PGM percentage extractions after 30 days

\begin{tabular}{llll}
\hline$\%$ & & & \\
$\mathbf{P t}$ & Pd & Ru & Rh \\
\hline 3.4 & 9.2 & 19 & 38 \\
\hline
\end{tabular}

The above mentioned solid assay also showed that with the exception of silicon there was a considerable amount of gangue element dissolution in the bioleach process (Table 4). But this is to be expected in an acid leach of ore containing gangue material with these elements. The elements that pose the most problems for bioleaching are $\mathrm{Mg}$ and $\mathrm{Al}$. Experiments conducted at bench scale indicate that $\mathrm{Mg}$ and $\mathrm{Al}$ inhibit ferrous iron oxidation at concentrations of 10-12 g/L (Ojumu et al., 2008). However the experimental data indicate that the average concentrations of $\mathrm{Mg}$ and $\mathrm{Al}$ during the experiment were $0.25 \mathrm{~g} / \mathrm{L}$ and $0.012 \mathrm{~g} / \mathrm{L}$ respectively. $\mathrm{As} \mathrm{Al}$ and $\mathrm{Mg}$ are not traditionally purged from heap leaching circuits, their build-up over time could constitute a problem, and this needs to be appropriately accounted for during process design.

Table 4: Gangue element percentage dissolution after 30 days

\begin{tabular}{ccccc}
\hline$\%$ & & & \\
$\mathbf{M g}$ & $\mathbf{A l}$ & $\mathbf{S i}$ & $\mathbf{C a}$ & $\mathbf{C r}$ \\
\hline 9.2 & 32 & 0 & 32 & 6.9 \\
\hline
\end{tabular}

\subsection{Cyanidation}

The metals rhodium and palladium responded well to the cyanide leach, compared to platinum and ruthenium (Table 5). The slope of the ruthenium extraction graph (Figure 4) although appearing flat in comparison with the other graphs, was actually increasing steadily by small increments as shown by the data. This may indicate first order behavior, but there was no indication that a maximum had been or would be reached soon. Platinum showed a similar trend, leaching at a comparably better rate but still slow. The platinum leach curve in Figure 4 is essentially linear and it suggests that there is a chance that a desired target of extraction could be achieved over a longer leaching period.

Table 5 shows the extractions of the BMs that remained after the bioleach process. Although copper and nickel extractions appear high, considering the amounts present in the ore concentrate 
relative to the PGMs, they did not exceed a concentration of $100 \mathrm{ppm}$ in solution. Further to this, the concentrations reduced to less $25 \mathrm{ppm}$ for copper and around $50 \mathrm{ppm}$ for nickel, with each subsequent re-freshing of solution as the leaching progressed. Beyond 100 ppm Marsden and House (2006) reported that copper can interfere with precious metal extraction through adsorption to carbon and cementation. Table 5 shows a low percentage extraction for iron compared to copper and nickel, but the concentration in solution was approximately 60-80 ppm with each re-fresh of solution. The percentage extraction appears low because the amount of iron in the concentrate was much higher than the copper and nickel. Like copper, iron is notorious for consuming cyanide in precious metal leaching and in sulphide mineral form; it also consumes oxygen which is necessary for the reaction between precious metals and cyanide (Chamberlain and Pojar, 1984). It is therefore necessary to let the bioleaching proceed until all iron sulphides are completely oxidised.

The extractions of the various major gangue elements were insignificant (Table 5) and this can be considered as an advantage for the cyanide treatment, owing to the fact that it will not consume large amounts of unwanted elements.

Table 5: PGM, BM and gangue metal extractions from cyanide heap leach

\begin{tabular}{lccccc}
\hline PGMs & Pt & Pd & Ru & Rh & \\
\% Extraction & 20.3 & 87 & 3.4 & 46 & \\
\hline BMs & $\mathbf{C u}$ & $\mathbf{N i}$ & $\mathbf{F e}$ & & \\
\% Extraction & 34 & 41 & 0.84 & & \\
\hline Gangue & $\mathbf{M g}$ & $\mathbf{C a}$ & $\mathbf{C r}$ & $\mathbf{A l}$ & $\mathbf{S i}$ \\
\% Extraction & 0.0038 & 0.38 & 0.0019 & 0 & 0.86 \\
\hline
\end{tabular}




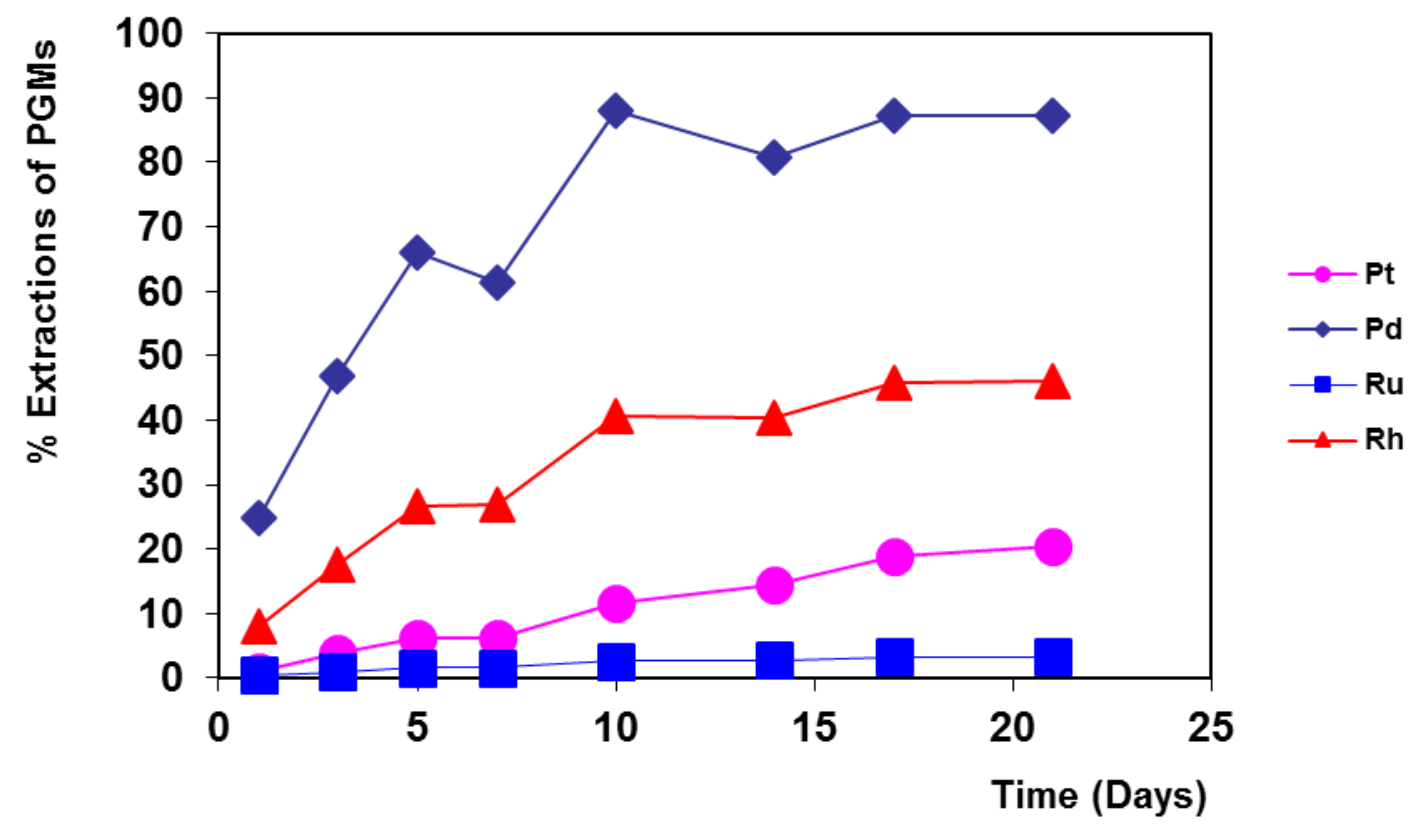

Figure 4: PGM extractions from cyanide heap leach

These results suggest that cyanidation as a chemical treatment could be a potentially viable option for commercial extraction of the key PGMs from the low-grade ore concentrate, although at relatively slow rates. Additionally, it has shown it does not consume any significant amounts of gangue elements. Complementing this process, a thermophilic heap bioleach process operating at a temperature of $65^{\circ} \mathrm{C}$ or possibly higher is a potentially promising route to extract the copper and nickel from the low-grade ore concentrate, for additional value and to reduce consumption of the cyanide lixiviant by these BMs although this process needs to achieve a high degree of completion.

\section{Flowsheet Development}

Based on the heap bioleach and cyanide experiments, the following process is proposed (Figure 5) to be incorporated into a standard platinum producing flowsheet. In this scenario, the highgrade concentrate streams will be processed via standard smelting of concentrate, acid pressure leaching of the matte and high pressure chloride leaching of high grade PGM residue. In parallel the low-grade concentrate streams will be processed as follows:

A heap bioleach run for 60 days or more to achieve the highest possible extraction of the BMs. The resulting copper-nickel-iron leach liquor would require the iron to be removed as an impurity. 
A standard platinum flowsheet achieves this by smelting of the ore concentrate before leaching. In the present case a hydrometallurgical iron removal step may be required depending on the amount of iron in solution and the subsequent requirements in a base metals refinery. The iron can be precipitated out as jarosite, goethite or hematite (Habashi, 1999; Gupta and Mukherjee, 1990; Ismael and Carvalho, 2003).

Once the iron has been removed the liquor can then proceed to a solvent extraction step to upgrade the solution to concentration levels that are suitable for recovery via conventional and well established processes used in current bioleach operations, namely sulphide precipitation (Riekkola-Vanhanen, 2010); solvent extraction-electrowinning (Sole et al., 2005; Dresher, 2004).

The concentrate can then be washed off the heap leach support material and washed with caustic water to raise the $\mathrm{pH}$ before coating it onto separate support material, for the leaching the PGMs with cyanide on a different heap. This frees up the previous heap area for another batch of material to be heap bioleached. The cyanide leach should be operated for 50 days or more to achieve $50 \%$ platinum extraction if the linear trend (from the cyanide leach experiment) in Figure 6 continues for the heap cyanide leach process. This will depend on the mineralogy of the platinum bearing minerals staying consistent for the duration of the leaching period.

At this stage the concentration of the PGMs in the solution is most likely to be in the $\mathrm{mg} / \mathrm{L}$ range and hence not suitable for recovery. To concentrate the solution, the metals are adsorbed to activated carbon in fluidised columns, after which they are stripped, through elution, using a smaller amount of hot cyanide solution to increase the concentration to the $\mathrm{g} / \mathrm{L}$ range and the metals can be recovered either by precipitation, zinc cementation or electrowinning. If the PGMs cannot be successfully eluted the other option is to burn off the carbon. In both cases a high grade residue product will be produced that can be further refined by blending with the conventional feed to an existing precious metal refinery process to obtain the PGMs. 


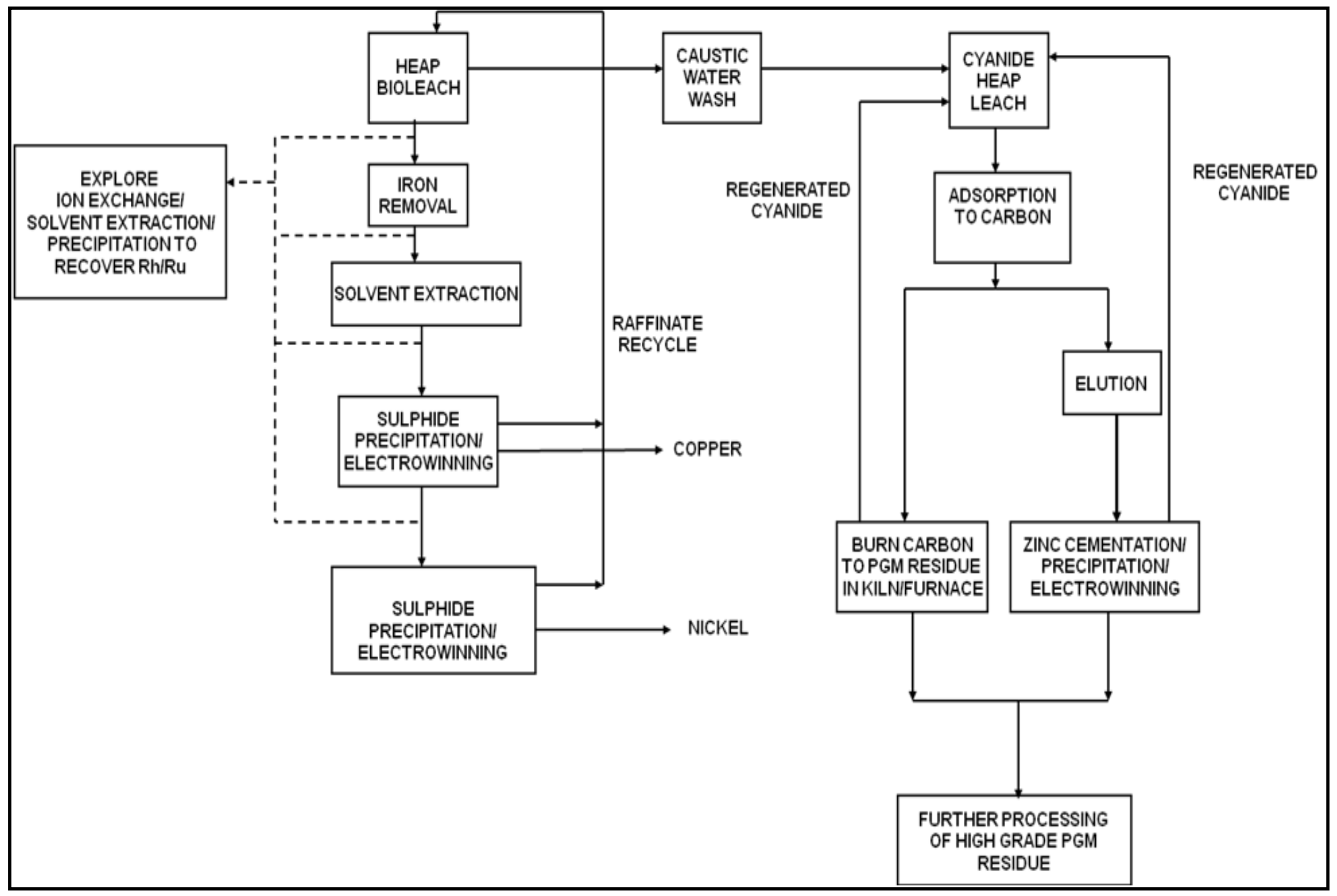

Figure 5: Flowsheet 


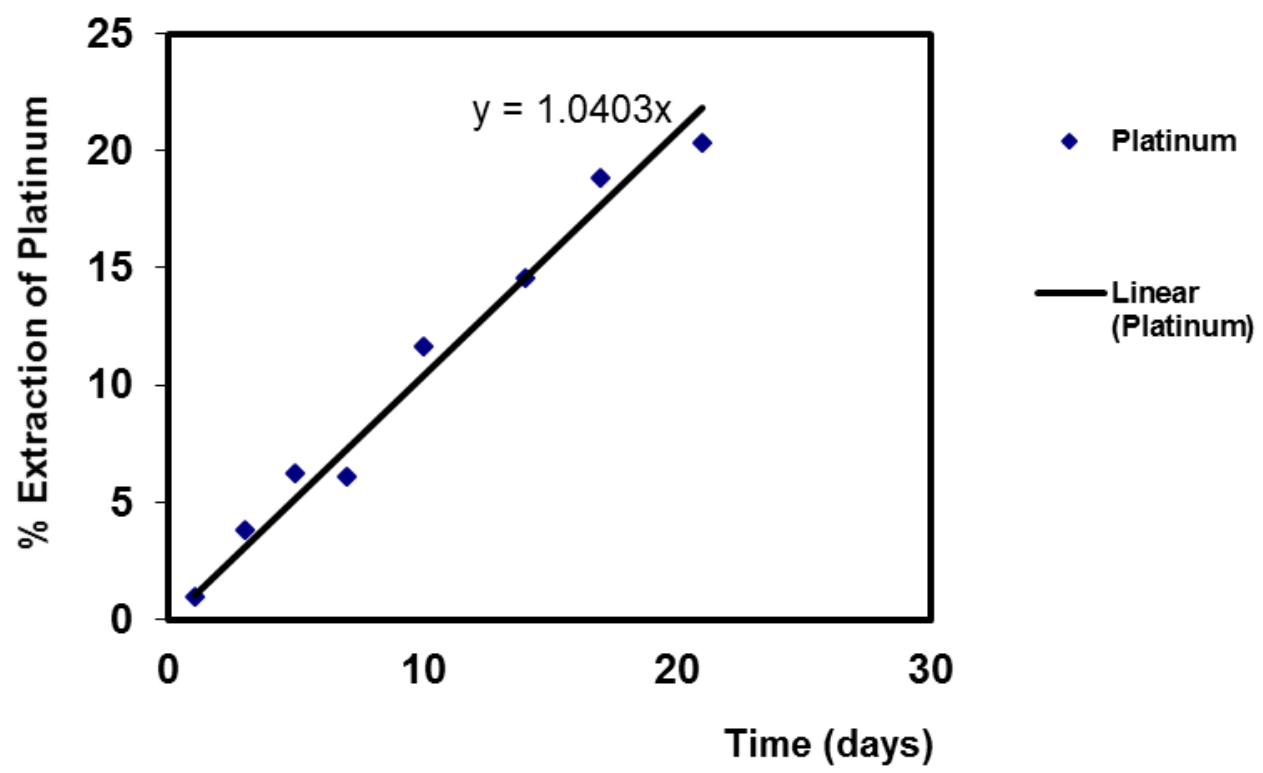

Figure 6: Platinum leach slope in cyanide heap leach test

\section{Conclusion}

This preliminary conceptual design is promising and is proposed as a potential method of economically extracting PGMs from low-grade flotation concentrates and possibly even tailings. However additional research work will still need to be conducted to determine the ultimate extent of PGM extractions achievable by cyanidation; to integrate the process into any existing process taking into consideration such factors as available real estate in proximity of the existing process for locating of heaps, and the suitability of the bioleach leach liquors and PGM residue produced, for blending with current feeds into existing base metal and precious metals refineries.

\section{Acknowledgements}

The authors would like to thank Lonmin Plc for funding this study and providing the test material. GEOCOAT $^{\odot}$ is a trademark process by Geobiotics of Lakewood, CO, USA.

\section{References}

Adams, M.D. (editor). 2005. “Advances in gold ore processing”. Developments in mineral processing, Mutis Liber Pty Ltd., Guildford, Western Australia. 
Akcil, A. 2002. "First application of cyanidation process in Turkish gold mining and its environmental impacts”, Minerals Engineering, volume 15, pp 695-699.

Akcil, A. 2003. "Destruction of cyanide in gold mill effluents: biological versus chemical treatments”, Biotechnology Avances, volume 21, pp 501-511.

Barriga-Ordonez, F., Nava-Alonso, F., Uribe-Salas, A. 2006. "Cyanide oxidation by ozone in steady-state flow bubble column”, Minerals Engineering, volume 19, pp 117-122.

Bernardis, F.L., Grant, R.A., Sherrington, D.C. 2005. "A review of methods of separation of the platinum-group metals through their chloro-complexes", Reactive \& Functional Polymers 65, pp 205-217.

Bosecker, K. 1997, “Bioleaching: metal solubilization by microorganisms”, FEMS Microbiology Reviews 20, pp 591-604.

Cabri, L.J. (Editor). 1989. “Platinum-Group Elements: Mineralogy, Geology, Recovery” CIM Special Volume 23, The Canadian Institute of Mining and Metalurgy, Quebec, Canada.

Cabri, L.J. (Editor). 2002, “The Geology, Geochemistry, Mineralogy and Mineral Beneficiation of Platinum-Group Elements”, CIM Special Volume 54, Canadian Institute of Mining, Metalurgy and Petroleum, Quebec, Canada.

Chamberlain, P.G., Pojar, M.G. 1984, "Gold and silver leaching practices in the United States”, Bureau of Mines Information Circular/1984, United States Department of the Interior IC 8969.

Chen, J., Huang, K. 2006, “A new technique for extraction of platinum group metals by pressure cyanidation”, Hydrometallurgy in China Journal, vol. 82, Issues 3-4, pp 164-171.

Cohn, J.G., Stern E.W., Etris S. F. 2001, "Gold and Gold Compounds”, Kirk-Othmer Encyclopedia of Chemical Technology-Online. Published online: 16 April, 2001. Retrieved: 8 October, 2007, from http://www.mrw.interscience.wiley.com/emrw/9780471238966 /kirk/article/goldcohn.a01/current/pdf.com/emrw/9780471238966 
Dash, R.R., Gaur, A., Balomajumder, C. 2009. "Cyanide in industrial waste waters and its removal: A review on biotreatment”, Journal of Hazardous Materials, volume 163, pp 1-11.

Deveci, H., Yazici, E.Y., Alp, I., Uslu, T. 2006. “Removal of cyanide from aqueous solutions by plain and metal-impregnated granular activated carbons”, International Journal of Mineral Processing, volume 79, pp 198-208.

Dew, D.W., Van Buuren, C. McEwan, K. and Bowker, C. 2000. "Bioleaching of base metal sulphide concentrates: A comparison of high and low temperature bioleaching”. The Journal of The South African Institute of Mining and Metallurgy, vol. 100, no. 07, pp 409-414.

Ding, J., Gao, J., Wu, X., Zhang, C., Wang, D., Qiu, G. 2007. “Jarosite-type precipitates mediated by YN22 Sulfobacillus thermosulfiooxidans, and their influences on strain". Transactions of Nonferrous Metals Society of China, volume 17, issue 5, pp 1038-1044.

Dixon, D.G. 2000. “Analysis of heat conservation during copper sulphide heap leaching”, Hydrometallurgy, vol. 58, issue 1, pp 27-41.

Dorfling, C., Akdogan, G., Bradshaw, S.M., Eksteen, J.J. 2010. “Determination of the relative leaching kinetics of $\mathrm{Cu}, \mathrm{Rh}, \mathrm{Ru}$ and Ir during the sulphuric acid pressure leaching of leach residue derived from $\mathrm{Ni}$-Cu converter matte enriched in platinum group metals, Minerals Engineering”. Article Published Online at http://dx.doi.org/10.1016/j.mineng.2010.08.021, 2010

Dresher, W.H. 2004, “Producing copper nature's way: bioleaching”. Retrieved: 3 September, 2007, from http://www.copper.org/innovations/2004/05/producing_copper_natures_way_ bioleaching.html.

Els, E.R., Lorenzen, L., Aldrich, C. 2000. "The adsorption of precious metals and base metals on a quaternary ammonium group ion exchange resin”, Minerals Engineering, vol. 13, no. 4, pp 401-414 
Evans, T. 2007, "Comments on Bioleaching of PGMs to accompany Report Nos. 102/CON/MS0006/SB and 111/MS030/SB”, Lonmin Plc.

Fatma, G., Ciftci, H., Akcil, A. 2009. “Biodegradation of cyanide containing effluents by Scenedesmus obliquus”, Journal of Harzardous Materials, volume 162, pp 74-79.

Gericke, M., Govender, Y., Pinches, A. 2010. “Tank bioleaching of low-grade chalcopyrite concentrates using redox control”, Hydrometallurgy, volume 104, pp 414-419.

Gonen, N., Kabasakal, O.S., Ozdil, G. 2004. "Recovery of cyanide in gold leach waste solution by volatilization and absorption”, Journal of Hazardous Materials B113, pp 231-236.

Gonzalez, R., Gentina, J.C., Acevedo, F. 2004, "Biooxidation of a gold concentrate in a continuous stirred tank reactor: mathematical model and optimal configuration”, Biochemical Engineering Journal, vol. 19, pp 33-42.

Gupta, C.K., Mukherjee, T.K. 1990, “Hydrometallurgy in Extraction Processes Volume II", CRC Press, Boston.

Habashi, F. 1999. “Textbook of Hydrometallurgy”, Second Edition, Les Copies de la Capitale Inc, Quebec City.

Harvey, T.J., Holder, N., Stanek, T. 2002. "Thermophilic bioleaching of chalcopyrite with GEOCOAT ${ }^{\circledR}$ Process", Presented at Alta 2002 Nickel/Cobalt 8-Copper 7 Conference, Perth, Australia

Ismael, M.R.C., Carvalho, J.M.R. 2003, "Iron recovery from sulphate leach liquors in zinc hydrometallurgy”, Minerals Engineering, vol. 16, pp 31-39. journal/0304386X.

Kinnunen, P.H.-M., Heimala, S., Riekkola-Vanhanen, M.-L., Puhakka, J.A. 2006. "Chalcopyrite concentrate leaching with biologically produced ferric sulphate”, Bioresource Technology 97, pp 1727-1734. 
Kitis, M., Akcil, A., Karakaya, E., Yigit, N.O. 2005. "Destruction of cyanide by hydrogen peroxide in tailings slurries from low bearing sulphidic gold ores”, Minerals Engineering, volume 18 , pp 353-362.

Kononova, O.N., Melnikov, A.M., Borisova, T.V., Krylov, A.S. 2011. "Simultaneous ion exchange recovery of platinum and rhodium from chloride solutions", Hydrometallurgy, vol. 105, Issues 3-4, pp 341-349.

Leahy, M.J., Schwarz, P.M. 2009, “Modelling jarosite precipitation in isothermal chalcopyrite bioleach columns”, Hydrometallurgy, vol. 98, Issues 1-2, pp 181-191.

Lien, L. 2008, “H W Process technologies' Engineered Membrane Separation ${ }^{\circledR}\left(\right.$ EMS $\left.^{\circledR}\right)$ systems for hydrometallurgical applications”, Proceedings for Hydrometallurgy 2008-6th International Symposium, Society of Mining, Metallurgy and Exploration , 17-20 August 2008, J W Marriot Desert Ridge Resort, Phoenix, Arizona.

Marsden, J., House, I. 2006, “The Chemistry of Gold Extraction”, Society of Mining, Metallurgy and Exploration. Second Edition, Colorado, USA

McInnes, C., M., Sparrow, G., J., Woodcock, J., T. 1994, “Extraction of Platinum, palladium, and gold by cyanidation of Coronation Hill ore”, Hydrometallurgy, vol. 35, pp 141-159.

Mular, A.L., Halbe, D.N., Barratt, D.J. 2002. “Minerals Processing Plant design, Practice, and Control-Proceedings”, volume 2, Society for Mining, Metallurgy, and Exploration, Inc. (SME).

Mwase, J.M. 2009. "Hydrometallurgical extraction of platinum group metals from a low-grade ore concentrate”, MSc thesis, Department of Chemical Engineering, University of cape Town.

Ojumu, TV, Petersen, J, Hansford, G.S. 2008. "The effect of dissolved cations on microbial ferrous-iron oxidation by Leptosprillum ferriphilum in continuous culture”, Hydrometallurgy, vol. 94, pp 64-76 
Ozel, Y.K., Gedikli, S., Aytar, P., Unal, A., Yamac, M., Cabuk, A., Kolankaya, N. 2010.

“New fungal biomasses for cyanide biodegradation", Journal of Bioscience and Bioengineering, volume 110 No. 4, pp 431-435

Parga, J.R., Shukla, S.S., Carrillo-Pedroza, F.R. 2003. "Destruction of cyanide using chlorine dioxide, ozone and titania sol”, Waste Management, volume 23, pp183-191.

Patil, Y.B., Paknikar, K.M. 2000. "Development of a process for biodetoxification of metal cyanides from waste waters”, Process Biotechnology, volume 35, pp 1139-1151.

Petersen, J. and Dixon, D.G. 2002, “Thermophilic Heap Leaching of A Chalcopyrite Concentrate”, Minerals Engineering, vol. 15 (11), pp 777-785.

Qin, W., Zhen, S., Yan, Z., Campbell, M., Wang, J., Liu, K., Zhang, Y. 2009. “Heap bioleaching of a low-grade nickel-bearing sulfide ore containing high levels of magnesium as olivine, chlorite and antigorite”. Hydrometallurgy, vol. 98, pp 58-65.

Rawling, D.E., Johnson, D.B. (editors) 2007. “Biomining”, Springer-Verlag Berlin Heidelberg, New York.

Riekkola-Vanhanen, M. 2010. "Production Technologies: Talvivaara Mining Company Plc”, Talvivaara Technical Seminar May 2010 presentation.

Schouwstra, R., P.; Kinloch, E., D. 2000, “A short geological review of the Bushveld Complex”, Platinum Metals Review, vol. 44, Issue 1, pp33-39.

Seymour, R.J., O'Farrelly, J.I. 2001, “Platinum Group Metals”, Kirk-Othmer Encyclopedia of Chemical Technology-Online. Published online: 13 July, 2001. Retrieved: 22 September, 2007, from http://www.mrw.interscience.wiley.com/emrw/ 9780471238966/kirk/article/platseym.a01/current/pdf.

Sole, K.C., Feather, A.M., Cole, P.M. 2005. "Solvent extraction in southern Africa: An update of some recent hydrometallurgical developments", Hydrometallurgy, volume 78, pp 52-78. 
Stott,M.B., Watling, H.R., Franzmann, P.D., Sutton, D. 2000. "The role of iron-hydroxy precipitates in the passivation of chalcopyrite during bioleaching ", Minerals Engineering, vol. 13, No 10-1, pp 1117-1127.

Torres, V. M., Costa, R. S. 1997, "Recovery and production of gold and platinum-group metals by using cyanidation under pressure”, Braindex online database. Retrieved: 2 July, 2007 from http://www.braindex.com/patent_pdf/

Watling, H.R. 2008. “The bioleaching of nickel-copper sulfides”, Hydrometallurgy 91, pp 70-88.

Yeddou, A.R., Nadjemi, B., Halet, F., Ould-Dris, A., Capart, R. 2010. "Removal of cyanide in aqeous solution by oxidation with hydrogen peroxide in the presence of activated carbon prepared from olive stones”, Minerals Engineering, vol. 23, pp 32-39. 